\title{
Commensurate intergrowths in titanium monoboride precipitates
}

\author{
Usanee Kitkamthorn and Mark Aindow
}

\section{Department of Materials Science and Engineering, Institute of Materials Science, University of Connecticut, Storrs, CT 06269-3136, USA}

The addition of boron to Ti-based and TiAl-based alloys can refine the grain structure and this is usually accompanied by the formation of boride particles due to the low solid solubility of B. The borides can exhibit a remarkable diversity of morphologies and crystal structures, although most of these are TiB monoborides in the form of plates, needles, and/or ribbons. The equilibrium crystal structure for $\mathrm{TiB}$ is $\mathrm{B} 27$, but certain alloying additions (e.g. Nb, Ta) can stabilize the $\mathrm{B}_{\mathrm{f}}$ structure [1]. Such borides often contain high densities of planar defects and in our work we have studied these defect structures in two alloys: Ti-6-4 and Ti-44Al-4Nb-4Zr (at. \%), both modified with 1 at.\% B.

The alloys were prepared by transferred-arc plasma melting with $\mathrm{B}$ in the form of $\mathrm{AlB}_{12}$. TEM samples were prepared by twin-jet electropolishing using an electrolyte consisting of $6 \%$ perchloric acid, $34 \%$ butanol and $60 \%$ methanol at $-15^{\circ} \mathrm{C}$ and $30 \mathrm{~V} / 40 \mathrm{~mA}$. The samples were then Ar+ ion milled for $0.5 \mathrm{~h}$ at $0.5 \mathrm{kV} / 0.2 \mathrm{~mA}$ to remove any residual contamination or damage layer on the surfaces. The CTEM experiments were performed in a Philips EM420T operating at $120 \mathrm{kV}$ whereas HRTEM lattice images were acquired using JEOL 2010 FasTEM equipped with a UHR objective lens polepiece $\left(\mathrm{C}_{\mathrm{s}} \approx 0.5 \mathrm{~mm}\right)$ and operated at $200 \mathrm{kV}$.

Preliminary SEM observations showed that the borides in B-modified Ti-6-4 were needle-like, whereas those in the B-modified Ti-44Al-4Nb-4Zr were curved ribbons. BF-TEM images (e.g. Fig. 1 (a) \& 2(a)) revealed that in both cases the borides contained planar faults parallel to the major facet. The needles in the B-modified Ti-6-4 consist of the B27-TiB phase and are oriented with [010] parallel to the needle axis (Fig. 1(a)). HRTEM images such as Fig. 1(b) reveal that the faults lie on (100), and that these correspond to thin coherent intergrowths of the $\mathrm{B}_{\mathrm{f}}-\mathrm{TiB}$ phase. The ribbons in the B-modified Ti-44Al-4Nb-4Zr are comprised of thin blocks with the $\mathrm{B}_{\mathrm{f}}-\mathrm{TiB}$ structure and having (010) as the major facet. These blocks contain a wide variety of different defect structures including pockets of metallic $\mathrm{B} 2$ phase, and coherent intergrowths of $\mathrm{Ti}_{3} \mathrm{~B}_{4}$ and $\mathrm{TiB}_{2}$ : all of these features lie parallel to $(010) \mathrm{B}_{\mathrm{f}}$ and the details of these structures are presented elsewhere [2]. Occasional faults were also observed lying parallel to (110) plane of $\mathrm{B}_{\mathrm{f}}$, and two examples are shown in Fig. 2(b). These latter faults correspond to thin embedded slabs of B27-TiB phase. Interestingly, in both the needles and the ribbons the orientation relationships between the $\mathrm{B}_{\mathrm{f}}-\mathrm{TiB}$ and $\mathrm{B} 27-\mathrm{TiB}$ phases is:

$$
[001] \mathrm{B}_{\mathrm{f}} / /[010] \mathrm{B} 27 \text {; with }\{110\} \mathrm{B}_{\mathrm{f}} / /(100) \mathrm{B} 27 \text {. }
$$

The $\mathrm{B}_{\mathrm{f}^{-}}$and $\mathrm{B} 27-\mathrm{TiB}$ structures are closely related, both comprising regular trigonal prisms with six $\mathrm{Ti}$ atoms at the vertices and one $\mathrm{B}$ atom at the center $[1,2]$. Although these prisms are arranged rather differently in the two structures, it is possible to produce the B27-TiB structure by repeated $180^{\circ}$ rotational twinning of the $\mathrm{B}_{\mathrm{f}}$ structure on $\{110\}$ (Figure 3). Similarly, $180^{\circ}$ rotational twinning of the B27 structure on (100) would produce $\mathrm{B}_{\mathrm{f}}$. As such, one would expect fully coherent interfaces, which would explain why the faults form on these planes. However, the faults are highly unlikely to form by a shear twinning mechanism in either of the alloy systems considered here: the orientation of the faults parallel to pronounced facets on the boride/metal interfaces suggests that they are instead probably the result of errors in the stacking sequence during growth. 


\section{References}

[1] M. De Graef, J. P. A. Lofvander and C. G. Levi. Acta Metall Mater 1991; 39: 2238

[2] U.Kitkamthorn, L. C. Zhang and M. Aindow. Intermetallics 2006: In press

[3] Work supported by NSF (Grant \# DMR DMR-0072721) and by the Royal Thai Government.

(a)

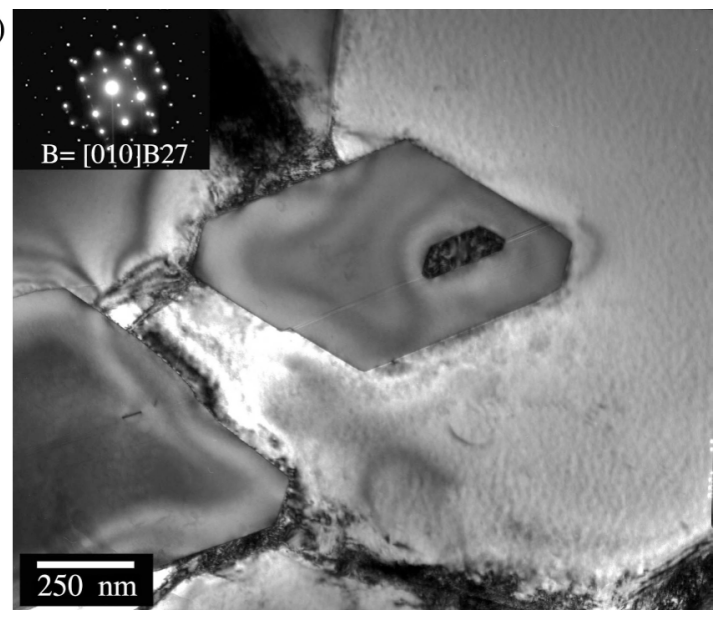

(b)

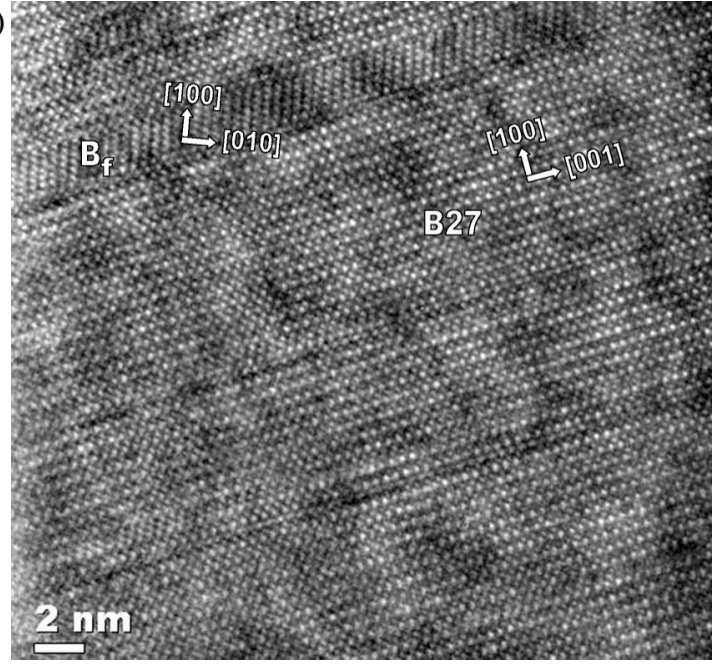

Fig. 1: BF-TEM (a), and HRTEM (b), images from a boride needle in B-modified Ti-6-4.

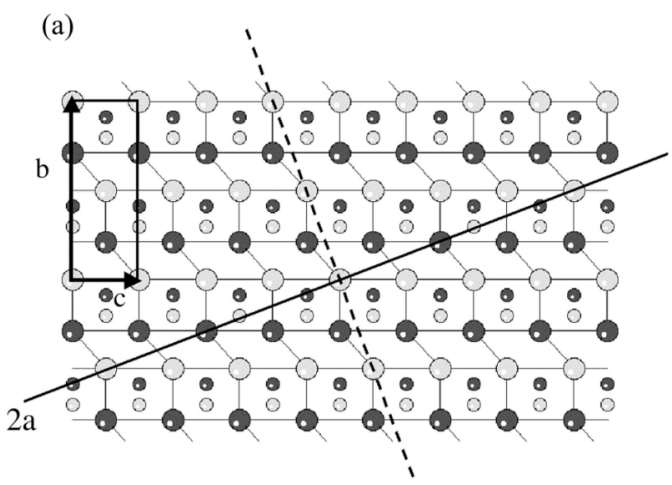

$[001] B_{\mathrm{f}}$ $\bigcirc$ Ti $1 / 4 \quad \bigcirc$ B $1 / 4$

- Ti 3/4 $\odot$ B $3 / 4$ (a)

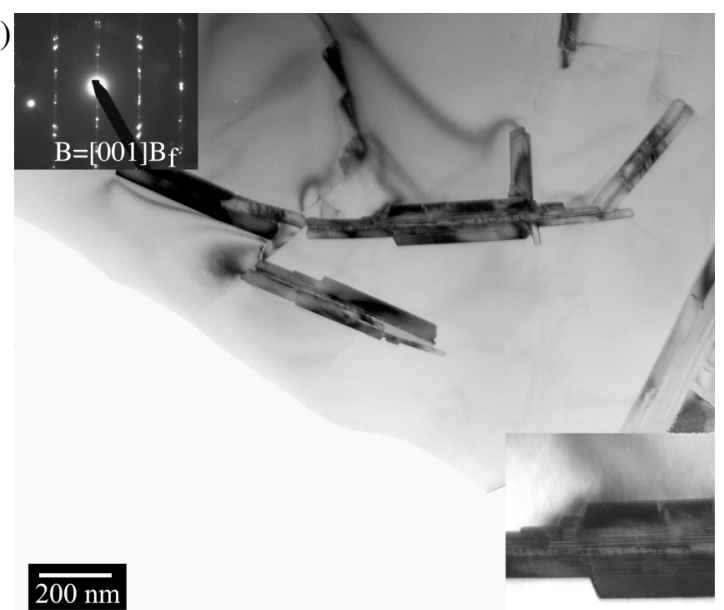

(b)

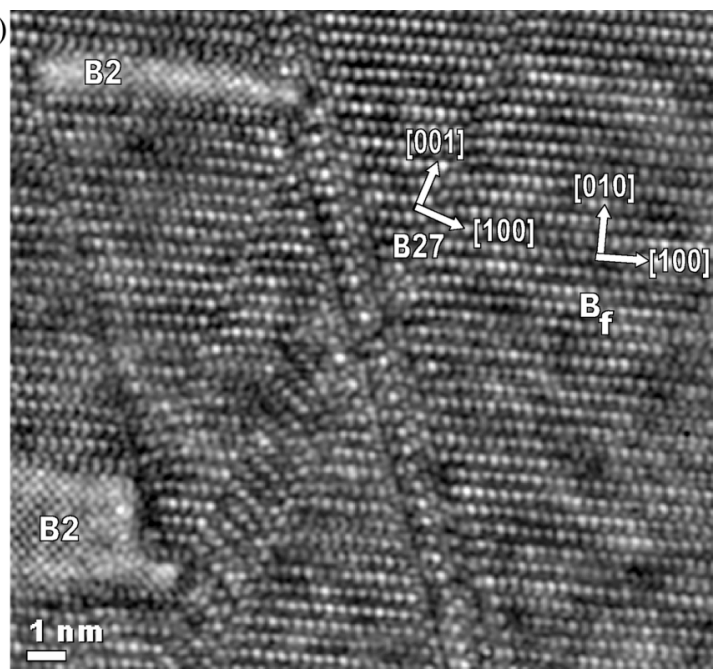

Fig. 2: BF-TEM (a), and HRTEM (b), images of a ribbon in B-modified Ti-44Al-4Nb-4Zr.

(b)

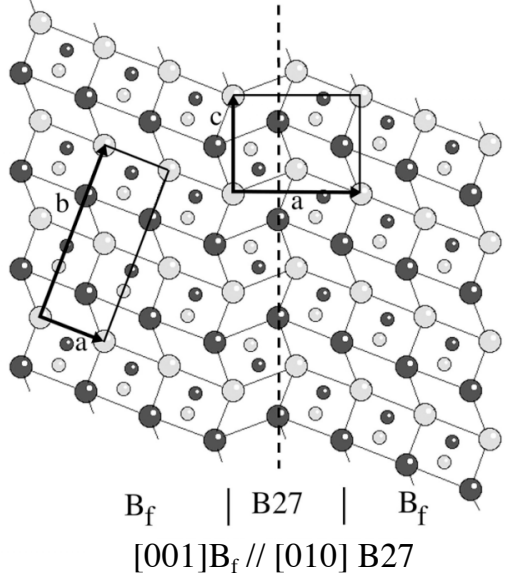

Fig. 3: Creation of a thin B27 layer at a $180^{\circ}$ twin on (110) in the $\mathrm{B}_{\mathrm{f}}$ structure [1] 